\title{
Nucleotide Synthesis Inhibition
}

National Cancer Institute

\section{Source}

National Cancer Institute. Nucleotide Synthesis Inhibition. NCI Thesaurus. Code C41592.

Nucleotide Synthesis Inhibition involves interference with, or restraint of, the activities of biologic molecules or complexes involved in the enzymatic formation of nucleoside phosphates, the monomeric building blocks from which DNA or RNA polymers are constructed. 